\title{
Application of Nanoparticles in Electrochemical Sensors and Biosensors
}

\author{
Xiliang Luo, Aoife Morrin, Anthony J. Killard, Malcolm R. Smyth* \\ School of Chemical Sciences, National Centre for Sensor Research, Dublin City University, Dublin 9, Ireland \\ *e-mail: malcolm.smyth@dcu.ie
}

Received: September 5, 2005

Accepted: October 17, 2005

\begin{abstract}
The unique chemical and physical properties of nanoparticles make them extremely suitable for designing new and improved sensing devices, especially electrochemical sensors and biosensors. Many kinds of nanoparticles, such as metal, oxide and semiconductor nanoparticles have been used for constructing electrochemical sensors and biosensors, and these nanoparticles play different roles in different sensing systems. The important functions provided by nanoparticles include the immobilization of biomolecules, the catalysis of electrochemical reactions, the enhancement of electron transfer between electrode surfaces and proteins, labeling of biomolecules and even acting as reactant. This minireview addresses recent advances in nanoparticle-based electrochemical sensors and biosensors, and summarizes the main functions of nanoparticles in these sensor systems.
\end{abstract}

Keywords: Nanoparticles, Sensors, Biosensors, Immobilization, Electron transfer, Enzyme, Electrochemistry

DOI: 10.1002/elan.200503415

Dedicated to Professor Petr Zuman on the Occasion of His $80^{\text {th }}$ Birthday

\section{Introduction}

Nanotechnology has recently become one of the most exciting forefront fields in analytical chemistry. A wide variety of nanomaterials, especially nanoparticles with different properties have found broad application in many kinds of analytical methods [1]. Owing to their small size (normally in the range of $1-100 \mathrm{~nm}$ ), nanoparticles exhibit unique chemical, physical and electronic properties that are different from those of bulk materials, and can be used to construct novel and improved sensing devices; in particular, electrochemical sensors and biosensors. Many types of nanoparticles of different sizes and compositions are now available, which facilitate their application in electroanalysis. Different kinds of nanoparticles, and sometimes the same kind of nanoparticles can play different roles in different electrochemical sensing systems, such as enzyme sensors, immunosensors and DNA sensors [2, 3]. Generally, metal nanoparticles have excellent conductivity and catalytic properties, which make them suitable for acting as "electronic wires" to enhance the electron transfer between redox centers in proteins and electrode surfaces, and as catalysts to increase electrochemical reactions. Oxide nanoparticles are often used to immobilize biomolecules due to their biocompatibility, while semiconductor nanoparticles are often used as labels or tracers for electrochemical analysis. Several reviews related to electrochemical sensors and biosensors based on nanomaterials have mentioned the important roles of nanoparticles, but few of them have systematically addressed the functions of nanoparticles [4, 5]. It is the aim of this minireview to summarize the recent advances in nanoparticle-based electrochemical sensors and biosensors and the functions of nanoparticles in these sensing systems.

\section{The Functions of Nanoparticles}

Many kinds of nanoparticles, including metal nanoparticles, oxide nanoparticles, semiconductor nanoparticles, and even composite nanoparticles, have been widely used in electrochemical sensors and biosensors. Although these nanoparticles play different roles in different electrochemical sensing systems based on their unique properties, the basic functions of nanoparticles can be mainly classified as: 1) immobilization of biomolecules; 2) catalysis of electrochemical reactions; 3) enhancement of electron transfer; 4) labeling biomolecules and 5) acting as reactant. The roles that different nanoparticles have played in electrochemical sensor systems are summarized in Table 1.

\subsection{Immobilization of Biomolecules}

Due to their large specific surface area and high surface free energy, nanoparticles can adsorb biomolecules strongly and play an important role in the immobilization of biomolecules in biosensor construction. Generally, the adsorption of 
Table 1. Different functions of nanoparticles in electrochemical sensor systems.

\begin{tabular}{|c|c|c|c|c|}
\hline Functions & Properties used & Typical nanoparticles & Sensor advantages & Typical examples \\
\hline $\begin{array}{l}\text { Biomolecule } \\
\text { immobilization }\end{array}$ & $\begin{array}{l}\text { Biocompatibility; } \\
\text { large surface area }\end{array}$ & $\begin{array}{l}\text { Metal nanoparticles } \\
\text { ( Au, } \mathrm{Ag}) \text {; } \\
\text { Oxide nanoparticles } \\
\left(\mathrm{SiO}_{2}, \mathrm{TiO}_{2}\right)\end{array}$ & Improved stability & $\begin{array}{l}\text { Antibody immobilized onto Au nanoparticles } \\
\text { remains stable for } 100 \text { days [18]. }\end{array}$ \\
\hline $\begin{array}{l}\text { Catalysis of } \\
\text { reactions }\end{array}$ & $\begin{array}{l}\text { High surface } \\
\text { energy }\end{array}$ & $\begin{array}{l}\text { Metal nanoparticles } \\
(\mathrm{Au}, \mathrm{Pt})\end{array}$ & $\begin{array}{l}\text { Improved sensitivity } \\
\text { and selectivity }\end{array}$ & $\begin{array}{l}\mathrm{H}_{2} \mathrm{O}_{2} \text { sensor based on Prussian Blue nanoparticles } \\
\text { with a sensitivity of } 103.5 \mu \mathrm{A} \mathrm{mM} \mathrm{mm}^{-1} \mathrm{~cm}^{-2}[34] .\end{array}$ \\
\hline $\begin{array}{l}\text { Enhancement } \\
\text { of electron } \\
\text { transfer }\end{array}$ & $\begin{array}{l}\text { Conductivity; } \\
\text { tiny dimensions }\end{array}$ & $\begin{array}{l}\text { Metal nanoparticles } \\
(\mathrm{Au}, \mathrm{Ag},) ; \\
\text { oxide nanoparticles } \\
\left(\mathrm{TiO}_{2}, \mathrm{ZrO}_{2}\right)\end{array}$ & $\begin{array}{l}\text { Improved sensitivity; } \\
\text { direct electrochemistry } \\
\text { of proteins }\end{array}$ & $\begin{array}{l}\text { Electron transfer rate of } 5000 \mathrm{~s}^{-1} \text { for glucose } \\
\text { oxidase enhanced by gold nanoparticles [36]. }\end{array}$ \\
\hline $\begin{array}{l}\text { Labeling } \\
\text { biomolecules }\end{array}$ & $\begin{array}{l}\text { Small size; } \\
\text { modifiability }\end{array}$ & $\begin{array}{l}\text { Semiconductor nano- } \\
\text { particles }(\mathrm{CdS}, \mathrm{PbS}) \\
\text { metal nanoparticles } \\
(\mathrm{Au}, \mathrm{Ag})\end{array}$ & $\begin{array}{l}\text { Improved sensitivity; } \\
\text { indirect detection }\end{array}$ & $\begin{array}{l}\text { DNA sensor labeled with Ag nanoparticles } \\
\text { achieves detection limit of } 0.5 \mathrm{pM}[47] \text {. }\end{array}$ \\
\hline $\begin{array}{l}\text { Acting as } \\
\text { reactant }\end{array}$ & Chemical activity & $\begin{array}{l}\text { Oxide nanoparticles } \\
\left(\mathrm{MnO}_{2}\right)\end{array}$ & $\begin{array}{l}\text { New response me- } \\
\text { chanism }\end{array}$ & $\begin{array}{l}\text { Lactate biosensor with } \mathrm{MnO}_{2} \text { nanoparticles re- } \\
\text { sponse } 50 \text { times more sensitive than without [55]. }\end{array}$ \\
\hline
\end{tabular}

biomolecules directly onto naked surfaces of bulk materials may frequently result in their denaturation and loss of bioactivity. However, the adsorption of such biomolecules onto the surfaces of nanoparticles can retain their bioactivity because of the biocompatibility of nanoparticles. Since most of the nanoparticles carry charges, they can electrostatically adsorb biomolecules with different charges. Besides the common electrostatic interaction, some nanoparticles can also immobilize biomolecules by other interactions. For example, it is reported that gold nanoparticles can immobilize proteins through the covalent bonds formed between the gold atoms and the amine groups and cysteine residues of proteins $[6,7]$.

Among the nanoparticles used for the immobilization of proteins, gold nanoparticles are probably the most frequently used [8]. In the early 1990s, Crumbliss et al. [9] immobilized several kinds of enzymes with gold nanoparticles and further fabricated different enzyme electrodes, and the prepared enzyme electrodes retained enzymatic activity. Chen et al. [10] firstly attached gold nanoparticles to gold electrodes modified with cysteamine monolayer, and then successfully immobilized horseradish peroxidase on these nanoparticles. They also studied the influence of nanoparticle size on the performance of the prepared biosensors and nanoparticles with smaller size were found to be more suitable for enzyme immobilization. Many similar studies have been reported for the construction of biosensors based on the immobilization of different proteins with gold nanoparticles, such as horseradish peroxidase [11, 12], microperoxidase-11 [13], tyrosinase [14] and hemoglobin [15]. $\mathrm{SiO}_{2}$ nanoparticles are also excellent matrices for enzyme immobilization due to their good biocompatibility and easy preparation. $\mathrm{Hu}$ et al. immobilized several heme proteins with $\mathrm{SiO}_{2}$ nanoparticles through the layer-by-layer assembly [16], and investigated the driving forces for the assembly procedure [17]. Other nanoparticles, such as Pt, $\mathrm{Ag}, \mathrm{TiO}_{2}, \mathrm{ZrO}_{2}$ nanoparticles and so on can also be used for the immobilization of enzymes.
Electrochemical immunosensors based on the immobilization of antigen or antibody with nanoparticles are also extensively studied. Yuan et al. [18] developed a reagentless amperometric immunosensor based on the immobilization of $\alpha$-1-fetoprotein antibody onto gold nanoparticles, and the immunosensor exhibited good long-term stability. They also prepared a label-free immunosensor for Japanese B encephalitis vaccine [19] through the immobilization of related antibody with gold nanoparticles. As antibodies and antigens are both proteins, their immobilization mechanism with nanoparticles is the same as the immobilization of enzymes. Besides the most frequently used gold nanoparticles, other nanoparticles such as silver [20] and silica [21] have also been used for the immobilization of antibodies and antigens.

Another kind of biomolecule, DNA, can also be immobilized with nanoparticles and used for the construction of electrochemical DNA sensors. In order to immobilize DNA onto the surfaces of nanoparticles, the DNA strands are often modified with special functional groups that can interact strongly with certain nanoparticles. Fang and coworkers [22] immobilized the oligonucleotide with a mercaptohexyl group at the 5 -phosphate end onto the $16 \mathrm{~nm}$ diameter gold nanoparticles, which were self-assembled on a cysteamine-modified gold electrode as shown in Scheme 1, and discovered that the saturated immobilization quantities of single-strand DNA on the modified electrode were about

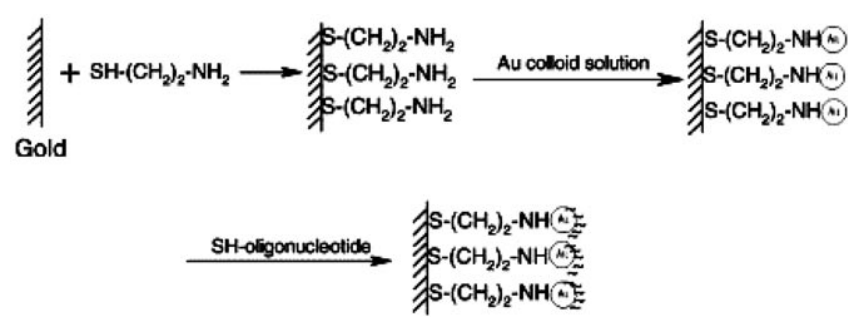

Scheme 1. The immobilization of DNA with gold nanoparticles (adapted from [22] with permission). 
10 times larger than that on a bare gold electrode. Recently, Yuan et al. [23] reported the immobilization of the same mercapto oligonucleotide with Ag nanoparticles attached to a thiol-containing sol-gel network. The immobilization of DNA with silica nanoparticles was also studied [24], and enhanced immobilization results were obtained.

In addition, nanoparticles can also be used to immobilize other materials besides biomolecules to develop electrochemical sensors. Related works can be found in the publications of Willner's group [25, 26].

Immobilization of biomolecules with certain nanoparticles can effectively increase the stability and maintain the activity of biomolecules, and it can be a good option for biomolecular immobilization. However, the shortcoming of this method is the inherent instability of some nanoparticles; for instance, their tendency to aggregate. It is hoped that the combination of this technique with suitable immobilization methods may resolve this problem.

\subsection{Catalysis of Electrochemical Reactions}

Many nanoparticles, especially metal nanoparticles have excellent catalytic properties. The introduction of nanoparticles with catalytic properties into electrochemical sensors and biosensors can decrease overpotentials of many analytically important electrochemical reactions, and even realize the reversibility of some redox reactions, which are irreversible at common unmodified electrodes. For instance, a sensitive NO microsensor was developed through the modification of a platinum microelectrode with gold nanoparticles in which gold nanoparticles catalyze the electrochemical oxidation of NO with an overpotential decrease of about $250 \mathrm{mV}$ [27]. The catalytic oxidation of NO can also be observed at dense gold nanoparticle film modified electrodes [28]. Based on the selective catalysis of nanoparticles, selective electrochemical analysis could be achieved. Ohsaka and coworkers [29] developed an electrochemical sensor for selective detection of dopamine in the presence of ascorbic acid, which was based on the catalytic effect of gold nanoparticles on the ascorbic acid oxidation. This resulted in the decrease of the oxidation overpotential of ascorbic acid and the effective separation of the oxidation potentials of ascorbic acid and dopamine, thus allowing the selective electrochemical detection.

Platinum nanoparticles are another type of nanoparticle that exhibit good catalytic properties and have been used in electrochemical analysis. Niwa et al. [30] prepared a highly sensitive $\mathrm{H}_{2} \mathrm{O}_{2}$ sensor based on the modification of a carbon film electrode with platinum nanoparticles. Due to the catalytic oxidation of $\mathrm{H}_{2} \mathrm{O}_{2}$ by platinum nanoparticles, the modified electrode exhibited sensitive response to $\mathrm{H}_{2} \mathrm{O}_{2}$, and the $\mathrm{H}_{2} \mathrm{O}_{2}$ oxidation peak potential at this electrode was about $170 \mathrm{mV}$ lower than that at platinum bulk electrode. As $\mathrm{H}_{2} \mathrm{O}_{2}$ is the product of many enzymatic reactions, the proposed electrode has the potential application as an electrochemical biosensor for many substances. Replacing platinum nanoparticles with $\mathrm{Ni}$ nanoparticles, the same group further developed an electrochemical sensor for sugar determination [31]. It was reported that a graphite-like carbon film electrode containing $0.8 \%$ highly dispersed $\mathrm{Ni}$ nanoparticles had excellent electrocatalytic ability with regard to the electrooxidation of sugars, such as glucose, fructose, sucrose and lactose. Compared with the Ni-bulk electrode, the proposed electrode exhibited a high oxidation current for the detection of sugars at comparatively low applied potentials, and the detection limits obtained were at least one order of magnitude lower. Electrochemical sensors based on the catalytic properties of other metal nanoparticles have also been reported, such as the application of copper nanoparticles for amino acid detection [32].

Some of the nonmetal nanoparticles that have special catalytic properties can also be applied in electrochemical analysis systems. For example, a carbon paste electrode doped with copper oxide nanoparticles was developed for the detection of amikacin based on the catalytic properties of the copper oxide nanoparticles [33], and the oxidation current of amikacin at the prepared electrode was about 40 times higher than that at a bulk copper oxide modified carbon paste electrode. Recently, Torresi et al. [34] reported the application of Prussian Blue nanoparticles in electrochemical sensing devices. Prussian Blue nanoparticles with the size of about $5 \mathrm{~nm}$ were immobilized onto ITO electrodes through the layer-by-layer technique, and the resulting electrodes exhibited sensitive responses to $\mathrm{H}_{2} \mathrm{O}_{2}(103.5 \mu \mathrm{A}$ $\mathrm{mM}^{-1} \mathrm{~cm}^{-2}$ for the electrode containing 15 bilayers) due to the catalytic reduction of $\mathrm{H}_{2} \mathrm{O}_{2}$ by the Prussian Blue nanoparticles.

The combination of the catalytic properties of nanoparticles with the unique properties of biosensors can result in the construction of highly sensitive sensor systems. CostaGarcia et al. [35] reported the monitoring of the biotinstreptavidin interaction based on silver electrodeposition catalyzed by gold nanoparticles on a carbon paste electrode, and the method could be used to determine streptavidin with a detection limit as low as $2 \mathrm{fM}$.

\subsection{Enhancement of Electron Transfer}

Electrical contacting of redox-enzymes with electrodes is a key process in the construction of third-generation enzymeelectrodes. While enzymes usually lack direct electrical communication with electrodes due to the fact that the active centers of enzymes are surrounded by considerably thick insulating protein shells, and the electron transfer between electrodes and the active centers are blocked, the conductivity properties of nanoparticles, mostly metal nanoparticles at nanoscale dimensions made them suitable for enhancing the electron transfer between the active centers of enzymes and electrodes acting as electron transfer "mediators" or "electrical wires".

A well-known example concerning the enhancement of electron transfer between enzyme and electrode with nanoparticles is the work of Willner's group [36]. As shown in Scheme 2, the $1.4 \mathrm{~nm}$ gold nanoparticles were function- 
alized with $\mathrm{N}^{6}$-(2-aminoethyl)-flavin adenine dinucleotide (1), and then reconstituted with apo-glucose oxidase and assembled on a thiolated monolayer associated with a gold electrode. Alternatively, the functionalized gold nanoparticles could be first assembled on the electrode, and apoglucose oxidase was reconstituted subsequently. The resulting enzyme electrode exhibited very fast electron transfer between the enzyme redox centre and the electrode with the help of the gold nanoparticles, and the electron transfer rate constant was found to be about $5000 \mathrm{~s}^{-1}$, which is about seven times faster than that between glucose oxidase and its natural substrate, oxygen. Moreover, the enzyme electrode could be used for glucose detection without interference, as the effective electrical contacting made it insensitive to oxygen or common interferants, such as ascorbic acid. The electron transfer between other redox proteins and electrodes have also been revealed with the help of gold nanoparticles. For example, Wang et al. [37] self assembled gold nanoparticles onto a three-dimensional silica gel networkmodified gold electrode, and obtained the direct electrochemistry of cytochrome $\mathrm{c}$. These gold nanoparticles acted as a bridge to electron transfer between protein and electrode.

Silver nanoparticles, as well as gold nanoparticles, have good conductivity, and they can also be used to enhance the electron transfer between proteins and electrodes. Li et al. [38] assembled silver nanoparticles on to pyrolytic graphite electrodes, and then immobilized cytochrome $c$ on these nanoparticles. It was reported that silver nanoparticles act as the electrical bridge that "wires" the electron transfer between cytochrome $\mathrm{c}$ and the electrode, and the electron transfer rate constant was about $15.8 \mathrm{~s}^{-1}$. The direct electron transfer between myoglobin and the electrode has also been elucidated by the same group with silver nanoparticles [39].

Some nonmetal nanoparticles, such as oxide nanoparticles and semiconductor nanoparticles, can also enhance the electron transfer between proteins and electrodes in certain systems. For instance, horseradish peroxidase was mixed with $\mathrm{TiO}_{2}$ nanoparticles and immobilized onto pyrolytic graphite electrodes, which resulted in direct electron transfer [40]. Hemoglobin immobilized with $\mathrm{ZrO}_{2}$ nanoparticles also exhibited direct electrochemistry at pyrolytic graphite electrodes and could be used for constructing mediator-free biosensors [41]. Other oxide nanoparticles such as $\mathrm{Fe}_{3} \mathrm{O}_{4}$ [42] and $\mathrm{MnO}_{2}$ [43] nanoparticles, have also been used to immobilize proteins and enhance their direct electrochemistry.

Recently, the application of semiconductor nanoparticles for the enhancement of electron transfer between redox proteins and electrode surfaces has been reported [44]. Hemoglobin and CdS nanoparticles were mixed and immobilized onto pyrolytic graphite electrodes, and the immobilized hemoglobin exhibited direct electrochemistry. In fact, the effective enhancement of electron transfer is

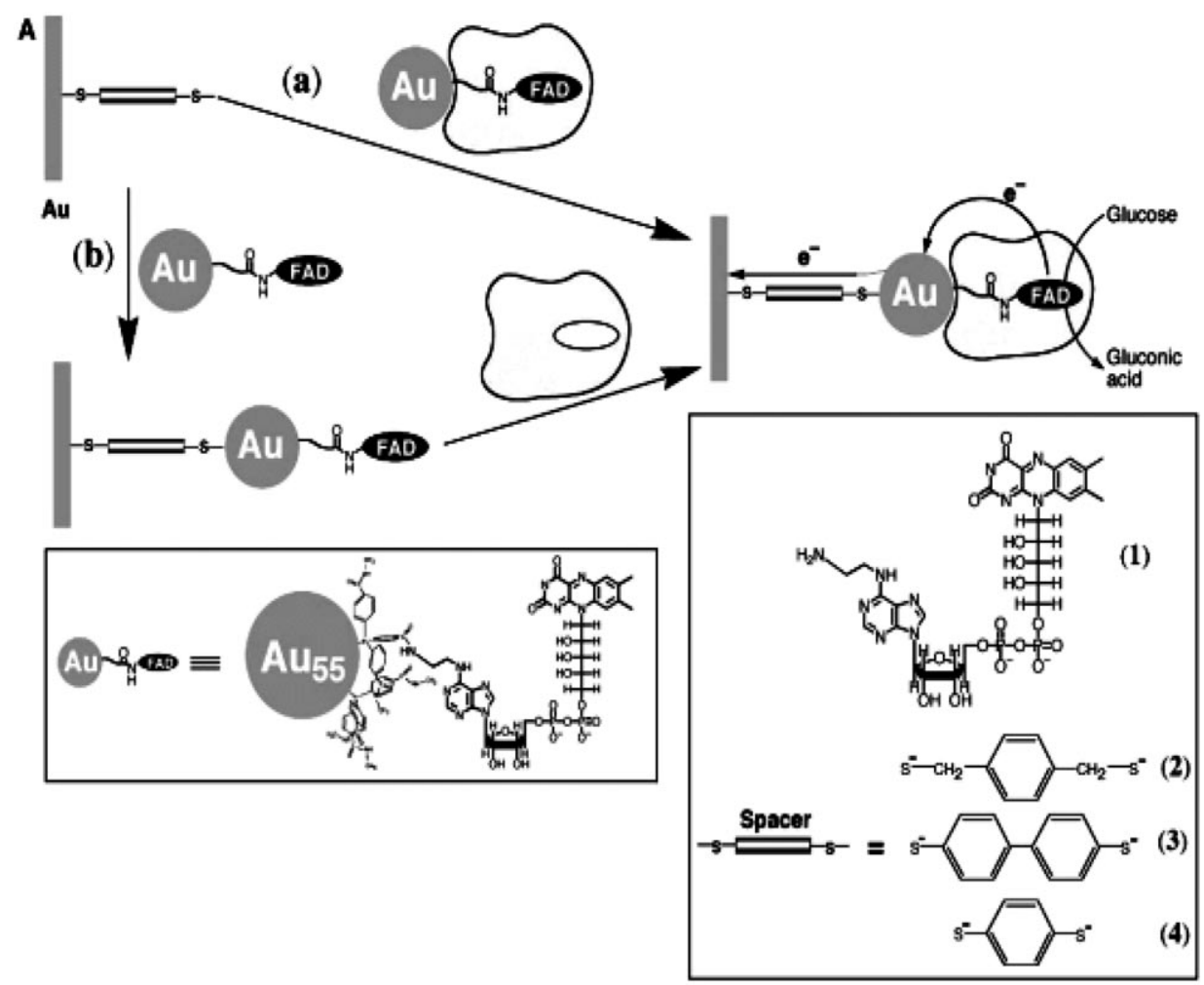

Scheme 2. Electrical coupling of gold nanoparticle-reconstituted glucose oxidase to an electrode by a) the adsorption of gold nanoparticle-reconstituted glucose oxidase to a dithiol monolayer associated with the gold electrode and b) the adsorption of gold nanoparticles functionalized with FAD on the dithiol-modified gold electrode followed by the reconstitution of apo-glucose oxidase on the functional nanoparticles (adapted from [35] with permission). 
dependent not only on the conductivity of nanoparticles, but also the arrangement between nanoparticles and biomolecules. It is believed that creating defined and ordered arrangements of nanoparticles using nanotechnology is a promising approach to the construction of biosensors with greatly enhanced electron transfer properties.

\subsection{Labeling Biomolecules}

The labeling of biomolecules, such as antigen, antibody and DNA with nanoparticles plays an increasingly important role in developing sensitive electrochemical biosensors. Biomolecules labeled with nanoparticles can retain their bioactivity and interact with their counterparts, and based on the electrochemical detection of those nanoparticles the amount or concentration of analytes can be determined. Dissolution of the nanoparticle labels - mostly metal and semiconductor nanoparticles - and measuring the dissolved ions with stripping voltammetry represents a general electroanalytical procedure, as stripping voltammetry is a very powerful electrochemical analytical technique for trace metal measurements [2].

Metal nanoparticle labels can be used in both immunosensors and DNA sensors, and gold nanoparticles are the most frequently used among all the metal nanoparticle labels available. For example, Limoges's group [45] has reported a sensitive electrochemical immunosensor for goat immunoglobulin $\mathrm{G}$ ( $\mathrm{IgG}$ ) based on a gold nanoparticle label, as shown in Scheme 3. The primary donkey anti-goat $\mathrm{IgG}$ was immobilized on a microwell surface and interacted with the goat $\mathrm{IgG}$ to be determined, and then gold nanoparticle-labeled donkey anti-goat IgG was added to conjugate with the analyte. The complex was treated with acidic bromine-bromide solution resulting in the oxidative dissolution of the gold nanoparticles. The solubilized gold ions were then electrochemically reduced and accumulated on the electrode and subsequently detected by anodic stripping voltammetry using carbon-based screen-printed electrodes. The combination of the sensitive detection of gold ions with anodic stripping voltammetry and the release of a large number of gold ions upon the dissolution of gold nanoparticle associated with a single recognition event provides an amplification path that allowed the detection of the goat $\mathrm{IgG}$ at a concentration of $3 \mathrm{pM}$. Employing a similar electrochemical method, Limoges et al. [46] further developed a sensitive DNA sensor based on the labeling of oligonucleotide with $20 \mathrm{~nm}$ gold nanoparticles, and the sensor could detect the 406-base human cytomegalovirus DNA sequence at a concentration of $5 \mathrm{pM}$.

Silver nanoparticles and certain core-shell metal nanoparticles have also been applied in the labeling of biomolecules for electroanalysis. It is reported that an electrochemical DNA biosensor based on a silver nanoparticle label could detect the target oligonucleotides at levels as low as $0.5 \mathrm{pM}$ [47]. Fang et al. [48] labeled 5'-alkanethiol capped oligonucleotide probes with gold-coated copper core-shell nanoparticles, and developed an electrochemical DNA sensor based on the indirect determination of solubilized $\mathrm{Cu}^{2+}$ ions by anodic stripping voltammetry. Similarly, Wang et al. [49] described a procedure for monitoring DNA hybridization based on electrochemical stripping detection of an iron tracer. They labeled the DNA probe with goldcoated iron core-shell nanoparticles and dissolved the ironcontaining nanoparticles following the DNA hybridization, and the released iron ions were determined by cathodic stripping voltammetry in the presence of the 1-nitroso-2naphthol ligand and a bromate catalyst.

In recent years, semiconductor nanoparticles have been extensively used as labels in electrochemical biosensors, especially DNA sensors [50]. For example, thiolated oligonucleotides labeled with CdS semiconductor nanoparticles were employed as tags for the detection of DNA hybridization events [51]. Dissolution of the CdS nanoparticles with $1 \mathrm{M}$ nitric acid, and the chronopotentiometric stripping measurements of the dissolved $\mathrm{Cd}^{2+}$ ions with a mercuryfilm electrode provided the electrical signal for the DNA analysis. Based on a similar principle, Wang et al. [52] developed a method for the simultaneous analysis of different DNA targets. Three different nucleic acids were immobilized on three different kinds of magnetic particles and hybridized with different DNA targets, and then DNA probes labeled with different semiconductor nanoparticles, such as $\mathrm{ZnS}, \mathrm{CdS}$ and $\mathrm{PbS}$ nanoparticles, were added and hybridized with their complementary DNA targets. Stripping voltammetry of the metal ions resulting from the

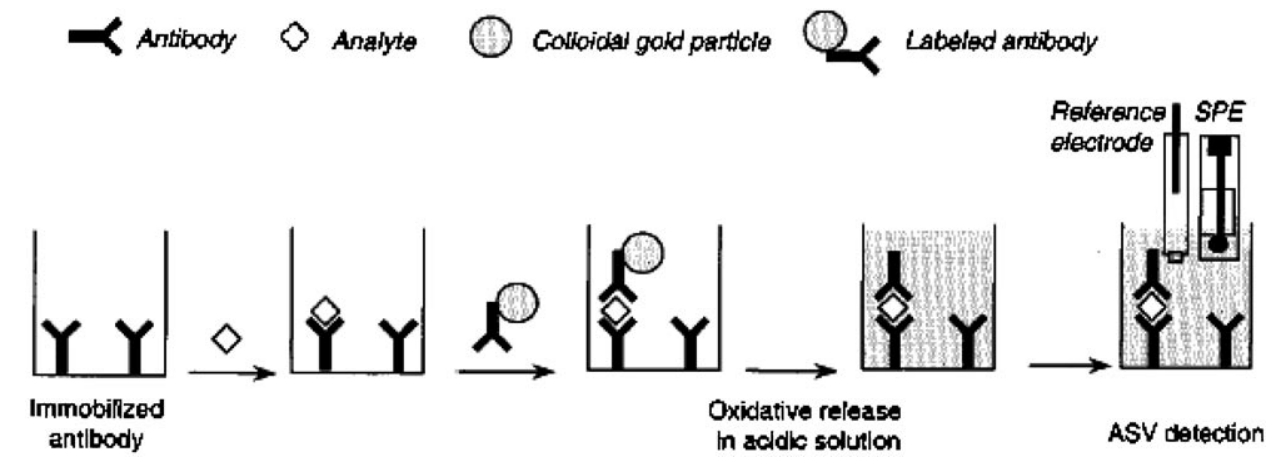

Scheme 3. Procedure of a noncompetitive heterogeneous electrochemical immunoassay based on a gold nanoparticle label (adapted from [45] with permission). 
dissolution of the semiconductor nanoparticles yielded welldefined and resolved stripping peaks at $-1.12 \mathrm{~V}(\mathrm{Zn})$, $-0.68 \mathrm{~V}(\mathrm{Cd})$ and $-0.53 \mathrm{~V}(\mathrm{~Pb})$ (vs. $\mathrm{Ag} / \mathrm{AgCl}$ reference), thus enabling simultaneous and sensitive electrochemical analysis of different DNA targets.

Oxide nanoparticles, in some circumstances, can also be used as labels for biomolecules. Fang and co-workers [53] have reported the application of tris $\left(2,2^{\prime}\right.$-bipyridyl) cobal$\left.\mathrm{t}(\mathrm{III})[\mathrm{Co}(\mathrm{bpy}))_{3}^{3+}\right]$ doped $\mathrm{SiO}_{2}$ nanoparticles as oligonucleotide labels for electrochemical detection of DNA hybridization. The $\mathrm{Co}(\mathrm{bpy})_{3}^{3+}$ doped $\mathrm{SiO}_{2}$ nanoparticles labeled DNA probe is used to hybridize with target DNA immobilized on glassy carbon electrodes, and only the complementary sequence DNA could form a double-stranded DNA with the probe. After the removal of unhybridized DNA probes, differential pulse voltammetry was performed to detect $\mathrm{Co}(\text { bpy })_{3}^{3+}$ inside $\mathrm{SiO}_{2}$ nanoparticles, which gave an obvious electrochemical response and allowed the detection at levels as low as $0.2 \mathrm{nM}$ of the target oligonucleotides.

Normally, electrochemical biosensors with nanoparticle labels are based on the final detection of the nanoparticle itself. Therefore, the preparation and application of special nanoparticle labels is of great importance. Composite nanoparticles with special components, for example, a core-shell nanoparticle with a shell suitable for labeling and a core containing special materials that can be sensitively detected with electrochemical methods, may play an important role in developing sensitive DNA sensors and immunosensors.

\subsection{Nanoparticles Acting as Reactant}

The chemical properties of some nanoparticles are different from those of the bulk materials, and normally the nanoparticles are chemically more active than the related bulk materials due to their high surface energy. For example, bulk $\mathrm{MnO}_{2}$ is known to catalyze the decomposition of $\mathrm{H}_{2} \mathrm{O}_{2}$, while $\mathrm{MnO}_{2}$ nanoparticles can react with $\mathrm{H}_{2} \mathrm{O}_{2}$ directly [54]. Taking advantage of the active properties of nanoparticles and using these nanoparticles as special reactants, some novel electrochemical analysis systems could be constructed.

Based on the special reactivity of $\mathrm{MnO}_{2}$ nanoparticles, Chen's group has developed several electroanalytical systems [54-57]. Glucose oxidase and $\mathrm{MnO}_{2}$ nanoparticles were coimmobilized on the gate of an ion-sensitive fieldeffect transistor (ISFET), and the resulting glucose biosensor showed a significant $\mathrm{pH}$ increase at the sensitive membrane with increasing glucose concentration, which is essentially different from the $\mathrm{pH}$ changes of conventional ISFET-based glucose biosensors [54]. Generally the response of an ISFET-based glucose biosensor is based on local $\mathrm{pH}$ changes in biomembranes resulting from the formation of gluconic acid, as in Reaction 1, while the driving force for $\mathrm{pH}$ change in the proposed biosensor is due to the special reaction of $\mathrm{MnO}_{2}$ nanoparticles with $\mathrm{H}_{2} \mathrm{O}_{2}$ as in Reaction 2.

$$
\begin{aligned}
& \beta \text {-D-glucose }+\mathrm{O}_{2}+\mathrm{H}_{2} \mathrm{O} \stackrel{\mathrm{GOD}}{\longrightarrow} \text { D-gluconate }+\mathrm{H}_{2} \mathrm{O}_{2}+\mathrm{H}^{+} \\
& \mathrm{MnO}_{2}+\mathrm{H}_{2} \mathrm{O}_{2}+2 \mathrm{H}^{+} \rightarrow \mathrm{Mn}^{2+}+2 \mathrm{H}_{2} \mathrm{O}+\mathrm{O}_{2}
\end{aligned}
$$

Thus the total reaction in the proposed glucose biosensor is given in Reaction 3:

$\beta$-D-glucose $+\mathrm{O}_{2}+\mathrm{MnO}_{2}+\mathrm{H}^{+} \stackrel{\mathrm{GOD}}{\longrightarrow}$

$+\mathrm{Mn}^{2}+$ D-gluconate $+\mathrm{H}_{2} \mathrm{O}$

Obviously, one hydrogen ion is consumed and no oxygen is needed in Reaction 3, which results in the novel response mechanism and extended dynamic range of the $\mathrm{MnO}_{2}$ nanoparticle-based glucose biosensor. Making use of a similar response mechanism, a sensitive biosensor for lactate was further developed based on layer-by- layer assembly of $\mathrm{MnO}_{2}$ nanoparticles and lactate oxidase on an ISFET [55], and its response to lactate was about 50 times higher than that of the biosensor without $\mathrm{MnO}_{2}$ nanoparticles.

$\mathrm{MnO}_{2}$ nanoparticles can also react with ascorbic acid, and a sensitive ISFET-based ascorbic acid sensor was constructed based on the reaction [56]. $\mathrm{MnO}_{2}$ nanoparticles were simply deposited on the gate of an ISFET, and its reaction with ascorbic acid resulted in the production of hydroxyl ions, which was related to the concentration of ascorbic acid that could be monitored by the ISFET. This ascorbic acid sensor was more stable and sensitive than the enzyme-based ISFET sensor, and it could be easily prepared and renewed. Moreover, the reaction of $\mathrm{MnO}_{2}$ nanoparticles with ascorbic acid has also been used to eliminate interference in a glucose biosensor [57]. A chitosan film containing $\mathrm{MnO}_{2}$ nanoparticles was introduced on the surface of an amperometric glucose biosensor, and the $\mathrm{MnO}_{2}$ nanoparticles could effectively oxidize ascorbic acid to an electrochemically inactive product before it reached the electrode surface.

The application of the special reactivity of nanoparticles in electrochemical sensors and biosensors has not been extensively studied, and more attention should be paid to this field. It is hoped that other nanoparticles besides $\mathrm{MnO}_{2}$ with unique reactive properties can be applied to the development of novel sensor systems. For instance, the properties of $\mathrm{PbO}_{2}$ and $\mathrm{CeO}_{2}$ are similar to that of $\mathrm{MnO}_{2}$, and nanoparticles based on $\mathrm{PbO}_{2}$ and $\mathrm{CeO}_{2}$ may also have special reactive properties which could be used to construct electrochemical sensors and biosensors.

\section{Future Perspectives}

This review has summarized the roles that nanoparticles play in electrochemical sensors and biosensors. The unique and attractive properties of nanoparticles have paved the way for the development of electroanalytical systems exhibiting attractive and promising analytical behaviors. Taking advantage of the special physical or chemical properties of nanoparticles, improved electrochemical sensors and biosensors can be constructed. For instance, 
biosensors with improved stability can be prepared using nanoparticles as substrates for biomolecule immobilization, while electrochemical sensors or biosensors with enhanced sensitivity and selectivity can be developed making use of the catalytic properties of nanoparticles.

Nanodimensional conducting polymers are emerging as another potentially beneficial material for electrochemical sensor and biosensor platforms. As with metallic nanoparticles, conducting polymer nanoparticles are known to exhibit unique properties such as greater conductivity and more rapid electrochemical switching speeds [58]. Moulton et al. [59] have synthesized a type of conducting polymer nanoparticle by a micellar emulsion chemical polymerization of polyaniline (PANI), using dodecylbenzenesulfonic acid (DBSA) as the micelle and dopant. These aqueous nanodispersions consisted of spherical particles with a diameter of $10 \pm 2 \mathrm{~nm}$ and had an electrical conductivity of $15 \pm 3 \mathrm{~S} \mathrm{~cm}^{-1}$. Modification of electrodes were readily achieved from this nanodispersion by both electrochemical [60] and casting methods [61]. Electrochemically formed films [60] were shown to comprise of nanostructured features, and could permit a highly effective uniform adsorption of protein.

As has been pointed out, one type of nanoparticle can play different roles in different electrochemical sensing systems, and it can also play more than one role in the same electroanalytical system. For example, our group has prepared two peroxide biosensors based on the polyaniline nanoparticles described above [60, 61]. These nanoparticles acted not only as substrates for the immobilization of horseradish peroxidase, but also as mediators for the enzyme to catalyze the reduction of $\mathrm{H}_{2} \mathrm{O}_{2}$ in the same sensor system. Moreover, the range of functions that nanoparticles display in electrochemical sensors and biosensors could also be extended to other nanomaterials, such as nanotubes and nanocomposites used in electroanalytical systems. Other nanomaterials, especially nanotubes have also been extensively used in the construction of many kinds of electrochemical sensors and biosensors [62]. However, the roles of nanotubes are mainly in the areas of the previous three aspects of functions we discussed. Nanocomposites are receiving increasing interest for sensor construction in recent years, and there may be breakthroughs in designing novel sensors with these materials, but it is believable that their roles in electrochemical sensors and biosensors will not go beyond the aspects summarized above.

\section{Acknowledgement}

The authors would like to acknowledge the support of Enterprise Ireland under the Technology Development Fund TD/03/107.

\section{References}

[1] S. G. Penn, L. He, M. J. Natan, Curr. Opin. Chem. Biol. 2003, 7, 609 .

[2] E. Katz, I. Willner, J. Wang, Electroanalysis 2004, 16, 19.

[3] J. Wang, Anal. Chim. Acta 2003, 500, 247.

[4] A. N. Shipway, E. Katz, I. Willner, Chemphyschem. 2000, 1, 18.

[5] J. Wang, Analyst 2005, 130, 421.

[6] A. Gole, C. Dash, V. Ramakrishnan, S. R. Sainkar, A. B. Mandale, M. Rao, M. Sastry, Langmuir 2001, 17, 1674.

[7] A. Gole, S. Vyas, S. Phadtare, A. Lachke, M. Sastry, Colloid. Surf. B 2002, 25, 129.

[8] S. Q. Liu, D. Leech, H. X. Ju, Anal. Lett. 2003, 36, 1.

[9] A. L. Crumbliss, S. C. Perine, J. Stonehuerner, K. R. Tubergen, J. Zhao, R. W. Henkens, Biotechnol. Bioeng. 1992, 40, 483.

[10] Y. Xiao, H. X. Ju, H. Y. Chen, Anal. Chim. Acta 1999, 391, 73.

[11] J. B. Jia, B. Q. Wang, A. G. Wu, G. J. Cheng, Z. Li, S. J. Dong, Anal. Chem. 2002, 74, 2217.

[12] X. L. Luo, J. J. Xu, Q. Zhang, G. J. Yang, H. Y. Chen, Biosens. Bioelectron. 2005, 21, 190.

[13] F. Patolsky, T. Gabriel, I. Willner, J. Electroanal. Chem. 1999, $479,69$.

[14] Z. M. Liu, H. Wang, Y. Yang, H. F. Yang, S. Q. Hu, G. L. Shen, R. Q. Yu, Anal. Lett. 2004, 37, 1079.

[15] H. Y. Gu, A. M. Yu, H. Y. Chen, J. Electroanal. Chem. 2001, $516,119$.

[16] P. L. He, N. F. Hu, Electroanalysis 2004, 16, 1122.

[17] P. L. He, N. F. Hu, J. F. Rusling, Langmuir 2004, 20, 722.

[18] Y. Zhuo, R. Yuan, Y. Q. Chai, D. P. Tang, Y. Zhang, N. Wang, X. L. Li, Q. Zhu, Electrochem. Commun. 2005, 7, 355.

[19] R. Yuan, L. Y. Zhang, Q. F. Li, Y. Q. Chai, S. R. Cao, Anal. Chim. Acta 2005, 531, 1.

[20] D. P. Tang, R. Yuan, Y. Q. Chai, L. Y. Zhang, J. Y. Dai, Y. Liu, X. Zhong, Electroanalysis 2005, 17, 155.

[21] H. Wang, J. S. Li, Y. J. Ding, C. X. Lei, G. L. Shen, R. Q. Yu, Anal. Chim. Acta 2004, 501, 37.

[22] H. Cai, C. Xu, P. He, Y. Fang, J. Electroanal. Chem. 2001, 510, 78.

[23] Y. Z. Fang, R. Yuan, L. Xu, Y. Q. Chai, Y. Liu, D. P. Tang, Y. Zhang, J. Biochem. Biophys. Methods 2005, 62, 163.

[24] D. Zhang, Y. Chen, H. Y. Chen, X. H. Xia, Anal. Bioanal. Chem. 2004, 379, 1025.

[25] A. N. Shipway, M. Lahav, I. Willner, Adv. Mater. 2000, 12, 993.

[26] A. N. Shipway, I. Willner, Chem. Commun. 2001, 2035.

[27] M. Zhu, M. Liu, G. Shi, F. Xu, X. Ye, J. Chen, L. Jin, J. Jin, Anal. Chim. Acta 2002, 455, 199.

[28] A. M. Yu, Z. J. Liang, J. H. Cho, F. Caruso, Nano Lett. 2003, 3, 1203.

[29] C. R. Raj, T. Okajima, T. Ohsaka, J. Electroanal. Chem. 2003, $543,127$.

[30] T. You, O. Niwa, M. Tomita, S. Hirono, Anal. Chem. 2003, 75, 2080.

[31] T. Y. You, O. Niwa, Z. L. Chen, K. Hayashi, M. Tomita, S. Hirono, Anal. Chem. 2003, 75, 5191.

[32] J. M. Zen, C. T. Hsu, A. S. Kumar, H. J. Lyuu, K. Y. Lin, Analyst 2004, 129, 841.

[33] J. Z. Xu, J. J. Zhu, H. Wang, H. Y. Chen, Anal. Lett. 2003, 36, 2723.

[34] P. A. Fiorito, V. R. Goncales, E. A. Ponzio, S. I. C. de Torresi, Chem. Commun. 2005, 366.

[35] M. B. Gonzalez-Garcia, A. Costa-Garcia, Biosens. Bioelectron. 2000, 15, 663. 
[36] Y. Xiao, F. Patolsky, E. Katz, J. F. Hainfeld, I. Willner, Science 2003, 299, 1877.

[37] L. Wang, E. K. Wang, Electrochem. Commun. 2004, 6, 49.

[38] T. Liu, J. Zhong, X. Gan, C. Fan, G. Li, N. Matsuda, Chemphyschem. 2003, 4, 1364.

[39] X. Gan, T. Liu, J. Zhong, X. J. Liu, G. X. Li, Chemphyschem. 2004, 5, 1686.

[40] Y. Zhang, P. L. He, N. F. Hu, Electrochim. Acta 2004, 49, 1981.

[41] S. Q. Liu, Z. H. Dai, H. Y. Chen, H. X. Ju, Biosens. Bioelectron. 2004, 19, 963.

[42] D. F. Dao, P. L. He, N. F. Hu, Analyst 2003, 128, 1268.

[43] Y. Lvov, B. Munge, O. Giraldo, I. Ichinnose, S. L. Suib, J. F. Rusling, Langmuir 2000, 16, 8850.

[44] H. Zhou, X. Gan, T. Liu, Q. L. Yang, G. X. Li, J. Biochem. Biophys. Methods 2005, 64, 38.

[45] M. Dequaire, C. Degrand, B. Limoges, Anal. Chem. 2000, 72, 5521.

[46] L. Authier, C. Grossiord, P. Brossier, B. Limoges, Anal. Chem. 2001, 73, 4450.

[47] H. Cai, Y. Xu, N. N. Zhu, P. G. He, Y. Z. Fang, Analyst 2002, 127, 803.

[48] H. Cai, N. N. Zhu, Y. Jiang, P. G. He, Y. Z. Fang, Biosens. Bioelectron. 2003, 18, 1311.

[49] J. Wang, G. Liu, A. Merkoci, Anal. Chim. Acta 2003, 482, 149.
[50] A. Merkoci, M. Aldavert, S. Marin, S. Alegret, $\operatorname{Tr} A C$, Trends Anal. Chem. 2005, 24, 341.

[51] J. Wang, G. Liu, R. Polsky, A. Merkoci, Electrochem. Commun. 2002, 4, 722.

[52] J. Wang, G. Liu, A. Merkoci, J. Am. Chem. Soc. 2003, 125, 3214.

[53] N. N. Zhu, H. Cai, P. G. He, Y. Z. Fang, Anal. Chim. Acta 2003, 481, 181.

[54] X. L. Luo, J. J. Xu, W. Zhao, H. Y. Chen, Biosens. Bioelectron. 2004, 19, 1295.

[55] J. J. Xu, W. Zhao, X. L. Luo, H. Y. Chen, Chem. Commun. 2005, 792.

[56] X. L. Luo, J. J. Xu, W. Zhao, H. Y. Chen, Anal. Chim. Acta 2004, 512, 57.

[57] J. J. Xu, X. L. Luo, Y. Du, H. Y. Chen, Electrochem. Commun. 2004, 6, 1169.

[58] P. Innis, G. Wallace, J. Nanosci. Nanotech. 2002, 2, 441.

[59] S. E. Moulton, P. C. Innis, L. A. P. Kane-Maguire, O. Ngamna, G. G. Wallace, Curr. App. Phys. 2004, 4, 402.

[60] A. Morrin, O. Ngamna, S. E. Moulton, A. J. Killard, G. G. Wallace and M. R. Smyth, Electroanalysis 2004, 17, 423.

[61] A. Morrin, F. Wilbeer, O. Ngamna, S. E. Moulton, A. J. Killard, G. G. Wallace and M. R. Smyth, Electrochem. Comm. 2005, 7, 317.

[62] J. Wang, Electroanalysis 2005, 17, 7. 